\title{
Comparison of the Performance of a Supply Chain Under Rebate and Option Contracts
}

\author{
Alejandra Gomez-Padilla \\ University of Guadalajara (UDG), Guadalajara, Jalisco, Mexico \\ Tsutomu Mishina \\ Akita Prefectural University, Yurihonjo, Akita, Japan
}

\begin{abstract}
The objective of this document is to compare the performance of the companies forming a dyadic supply chain, and for the chain as a single unit, under two types of contracts: option and rebate. The performance is measured in economic terms (benefits and costs) and in physical units (inventory held and unsatisfied demand). The results will help to identify which is the better contract for a given set of parameters. Under an option contract, the retailer orders a quantity of units and has a right to modify his order (increase or decrease) by buying the option premium in advance from the supplier. Under a rebate contract, the supplier offers a rebate for the units ordered over a certain number of units previously fixed. With an option contract, the retailer reserves a number of units from the supplier and, after receiving more information about demand, he will pass his final order. With a rebate contract, the retailer will decide from the beginning the number of units to order knowing the rebate condition (price and quantity). First the theoretical bases are introduced for each contract, next both models are compared by simulation. The simulation plan is presented and the results are discussed.
\end{abstract}

Keywords: Supply chain, Contracts, Rebate, Option.

\section{Introduction}

Supply chains need coordination to afford the sources of variation and uncertainty. Cooperation improves the results for the companies (Liu and Wang, 2007). Some sources of uncertainty why companies need to coordinate are the requirements, the available capacity of the supplier (Jain and Silver, 1995) and inventory decisions (Jin and $\mathrm{Wu}, 2007)$. Contracts help the members of the chain to coordinate their decisions, since it is by contracts that the companies in a supply chain are going to establish parameters that will influence their operational decisions and in consequence their economic results. This document studies the coordination by contracts, comparing a contract where there is not coordination and a coordinating contract which coordinates by reducing the uncertainty of requirements. A contract may be oriented, for example, to incite the retailer to increase his stock. To do so, the supplier may reduce prices or share the risk that holding inventory represents. This work focus on the study of two types of contracts in a supply chain: rebate and option. Both contracts have been widely 
studied. In has been found that the rebate contract may coordinate a supply chain for specific situations: when the rebate is sales - based (Taylor, 2002), when combined with return policies (Zhang et al., 2005) and (Lu et al., 2007). None of these situations are considered in this document, so the rebate contract will not coordinate the chain. The option contract is relatively new, so the literature focuses mainly on the model analysis (Wang and Tsao, 2005) and how it should operate (Schneeweiss et al., 2004; Kamrad and Siddique, 2004; Edlin and Hermalin, 2000) rather than coordination mechanisms. The motivation of this research was to compare the performance of two contracts: one that will not coordinate but is simple (rebate) and one that may coordinate but implies cooperation to decide the value of the parameters.

A rebate contract, as considered in this document, is oriented to incite the retailer to increase his stock. The supplier does so by offering the retailer an advantageous price if he orders a bigger quantity. With a rebate contract three parameters must be fixed: the wholesale price, the rebate price and the target or level from which the units will be subject to the rebate. With an option contract, the supplier will share the risk of variation on demand. In this contract the supplier fix a price for the units and both retailer and supplier will agree on an option premium. The option premium is a sum to be paid to the supplier when the final order is modified, and is calculated from the expected demand. Under both contracts, rebate and option, the retailer will order a number of units to replenish his stock, but with an option contract, the retailer will have the right to modify this order, decreasing or increasing it, by a previous payment of an option premium. In this document, it is modeled first the situation for one retailer with multiple suppliers, and then the situation for one retailer and one supplier. The model was done supposing both types of contracts between retailer and supplier: rebate and option contract. The objective is to compare the results in terms of units (inventory hold and lost sales) and in economic terms (gains and benefit for the chain).

This document first presents the literature survey concerning rebate and option contracts. Next, the models for one retailer and multiple suppliers and for one retailer and one supplier are introduced. The difference between the contracts lies on the amount that the retailer has to pay to the supplier (transfer); this sum to pay is calculated according to the parameters each contract has. The simulations are for a uniformly distributed demand under 12 different situations for the dyadic model. The situations differ on the values given to the parameters, and consist on different rebate schemes for the rebate contract and different conversion rates to calculate the option premium in the option contract. The results of simulation are discussed before concluding.

\section{Literature Review}

Contracts have been studied from several points of view, and coordination is one of them. Coordination is studied because the decisions have to be taken considering forecasts, and forecasts may lack accuracy. (Liu and Wang, 2007) concluded that cooperation improve the results for the companies on a supply chain with exogenous market demand, price and manufacturing costs. Contracts will affect the procurement of products and the costs and benefits of the companies of a supply chain. (Jain and Silver, 1995) identify two types of uncertainty regarding procurement: 1) uncertainty with respect to the requirements (quantity and/or timing) and 2) uncertainty regarding the capability of the supplier, particularly with regard to available capacity. The contracts 
are then a mechanism to coordinate decisions. In this document two contracts are studied: rebate and option. A rebate contract doesn't need cooperation: the retailer will order a number of units and the rebate will depend on the number of units. An option contract needs cooperation between the contracting companies because the retailer will pass two orders: the first one is an estimation and the second one is the final order; the supplier must be able to satisfy this order that may be higher or lower than the initial one. Cooperation is needed in an option contract since the supplier and the retailer must agree on how the option premium will be calculated. The contracts will affect the decisions concerning the inventory hold by the retailer. (Jin and $\mathrm{Wu}, 2007$ ) analyze how to coordinate by inventory decisions.

In the related literature it is possible to find several quantity discount contracts. The differences between them are on the characteristics of the market were the product will be sold and on the reasons for the discount. Quantity discounts have been studied for markets where the discount depends on the time when demand takes place, sales, price, lead time, effort, and when discount is independent. Rebate contracts are a type of quantity discounts contracts; they depend on the quantity of units ordered by the retailer. (Chiu et al., 2011) identify 3 rebate programs (they call them "scan back" as (Kurata and Yue, 2008)): linear, target and progressive. A linear rebate takes place when it exist a fixed rebate per unit, a target rebate occurs when a rebate is fixed per unit beyond a pre-specified target, and progressive rebate happens when tiers are fixed and the rebate is progressive depending on the tiers. Even though they are associated to sales-based rebates, these three programs are valid for other types of market characteristics. (Gu and Yang, 2010) analyse a particular situation of quantity discount in terms of difference in package size (small or large) and the perception of costumers. The rebate modelled by (Gu and Yang, 2010) is target. (Taylor, 2002) found that this type of rebate may coordinate a supply chain when a sales-based situation is studied. (Zhang et al., 2005) show that a target rebate contract combined with return policies can coordinate a chain when demand is price independent. (Lu et al., 2007) coordinates a supply chain with a similar approach and they also combine with price protection policies. (Chiu et al., 2011) propose a policy combining wholesale price, channel rebate and returns for price-dependent demand. In a returns discount contract the important element are not ordered quantities, but unsold quantities, as in (Chen, 2011). (Chen, 2011) study how to achieve coordination for the newsvendor problem under a wholesale price contract and propose a returns discount contract. In (Nocke et al., 2011) the rebate is linear for the totality of units (tickets in their case), and as time passes (time of demand approaches), the rebate diminishes; they conclude that complicated contracts as partial refund contracts cannot lead to higher profits. (Hassini, 2008) models a dynamic inventory replenishment considering multiple suppliers offering each different price discounts according to the lot size; this approach correspond to a progressive rebate where each supplier offers a different rebate scheme. Rebate contracts are an important issue of study since their growing application in several industries like retail (Chiu et al., 2011), fashion (Kurata and Yue, 2008), services (Nocke et al., 2011) and health, specifically pharmaceutical products (Natz, 2008).

Concerning option contracts, (Wang and Tsao, 2005) study bidirectional options; the options are exercised as calls and puts from the base of a wholesale price but depending on quantity variations. In (Schneeweiss et al., 2004) the retailer will pay the supplier (pay a premium) for supplying the ordered quantity knowing that the 
supplier can exert her option to not to satisfy the ordered quantity. (Edlin and Hermalin, 2000), with an agency theory approach, demonstrate that an option contract can prevent the principal to hold up the agent. For the newsvendor problem, (Yang and Qi, 2009) design contracts that coordinate the chain and (Kamrad and Siddique, 2004) model an option contract where the order levels are modified considering exchange rate fluctuations. (Bassok and Anupindi, 1997) model, for a two period horizon, a dyadic chain in which the retailer specifies a fix quantity to be bought each period and a number of extra units (or options) that the retailer may need. He will pay a fix sum to ensure the options, and if he finally orders them he pays a higher price. The authors identify the number of options to reserve to maximize the profit for the retailer. (Gomez-Padilla and Mishina, 2009) study an option contract and introduce the conversion rate, which is a parameter that helps to decide the premium to pay. They simulated conversion rates on (Gomez-Padilla and Mishina, 2009) go from 0.5 to 11, concluding that when the conversion rate is 1 , the supply chain achieves coordination. They showed that option contracts give better results than a buy back contract or a wholesale price contract. (Wang and Liu, 2007) analyze coordination for a situation where the retailer passes an initial order and reserves additional units, for which he pays an option price. In (Xu, 2010) a manufacturer buys the option to change his order after demand is observed; the price for this final order is random and depends on availability.

The approach of this document for rebate contract will be similar to target rebate since the units beyond a pre-specified target level will receive a fixed rebate. The units under this target will cost the regular wholesale price. In this research, the model considered for the option contract is like the bidirectional contract on (Wang and Tsao, 2005). The retailer has to pay to the supplier an option premium that will allow the retailer to modify the ordered quantity when he has a more precise information of demand. The difference from (Wang and Tsao, 2005) is that in this document, the sum to pay to the supplier depends on the variation of the ordered quantity and on the option premium. Demand is considered to be independent for both contracts.

\section{Model}

\section{Model Description}

The model considers first, the case where several suppliers provide an identical product to the retailer and next, a dyadic case with one supplier and one retailer. Two situations are considered, the first one with the companies in the chain linked with a rebate contract and the second one with the companies linked with an option contract. With the rebate contract the retailer orders a number of units and will receive this quantity from the supplier. With an option contract, one of the suppliers will permit that the retailer modifies the initially ordered quantity and in exchange the retailer will pay an option premium. We suppose that inventory is managed by a base stock policy, with no capacity constraints on the supplier side and zero delivery lead time.

At each period of time $t$, demand is an expected value $X(t)$. For a rebate contract, is important to know the demand distribution to determine the base stock level, and for an option contract, besides determining the base stock level, it is important to calculate the option premium that will be paid to the supplier. The option premium is calculated from four parameters: 1) the actual demand at the previous period of time: 
$D(t-1) ; 2)$ the average growth rate of demand: $r ; 3)$ the upper limit growth of demand: $u$ and 4 ) the lower limit growth of demand: $d$. With these parameters we calculate the higher expected demand at time $t: D u(t)$, and the lower expected demand at time $t$ : $D d(t)$. The demand at time $t$ depends on the demand of the previous period $(t-1)$, as shown by Figure 1.

$Q^{S i}(t)$ is the ordered quantity from the retailer to supplier $i$ at time $t$; with these ordered units the retailer will replenish his stock. $I^{R}(t)$ is the inventory hold by the retailer at time $t$; with this inventory he will satisfy demand over the final market. $J^{R}(t)$ are the units available by the retailer at time $t$. The stockout, backorder or unsatisfied demand of the retailer at time $t$, is $B^{R}(t)$. $S^{R}(t)$ represent the number of units sold by the retailer at time $t$. The retailer will sell the product on the final market at price $p(t)$ at time t. The production cost (or the cost of making the product available at the final market) at time $t$ is $c^{R}(t)$. The inventory holding cost of the retailer at time $t$ is $h^{R}(t)$. The opportunity cost at time $t$ is $\beta^{R}(t)$. TS $(t)$ is the transfer from the retailer to the suppliers at time $t$; his is, $\mathrm{TS}(\mathrm{t})=\sum_{\mathrm{i}=1}^{\mathrm{I}} T S^{S i}(t)$ where $T S^{S i}(t)$ is the transfer from the retailer to
supplier $i$ at time $t$.

Suppliers sell an identical product, and $S^{S i}(t)$ are the number of units sold from supplier $i$ to the retailer at time $t, B^{S i}(t)$ is the demand the supplier $i$ was not able to satisfy at time $t$ and $I^{S i}(t)$ is the inventory hold by supplier $i$ at time $t$. The units produced by supplier $i$ at time $t$ is $M^{\text {Si }}(t)$ and the units available by supplier $i$ at time $t$ is $J^{S i}(t)$. The costs that each supplier $i$ has to assume are: production $\operatorname{cost} c^{S i}(t)$, holding $\operatorname{cost} h^{S i}(t)$ and opportunity $\operatorname{cost} \beta^{S i}(t)$ (from backordered demand). The retailer and the suppliers have fix costs, represented respectively by $F C^{R}$ and $F C^{S i} \cdot \pi^{R}(t)$ is the profit of the retailer at time $t$. The profit of supplier $i$ at time $t$ is $\pi^{S i}(t)$. The profit of the chain is $\Pi(t)$ and it is the sum of profits of the retailer and the suppliers.

The benefit for the retailer is calculated from his revenue, minus the costs.

$$
\pi^{R}(t)=p(t) S^{R}(t)-c^{R}(t) \sum_{i=1}^{\mathrm{I}} S^{S i}(t)-h^{R}(t) l^{R}(t)-F C^{R}-T S(t)
$$

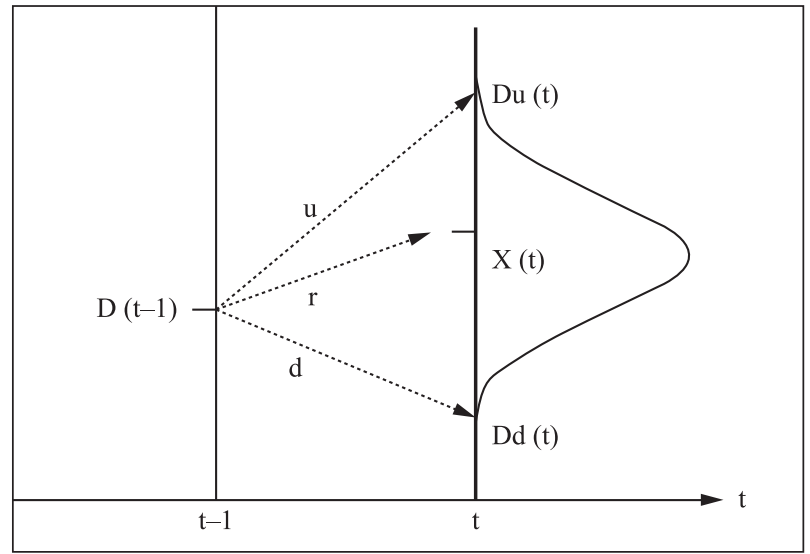

Figure 1. Parameters needed in an option contract concerning demand. 
The benefit of each supplier is calculated from the revenue received from the transfer from the retailer minus their costs (production, holding, stockout and fix).

$$
\pi^{S i}(t)=T S^{S i}(t)-c^{S i}(t) M^{S i}(t)-h^{S i}(t) I^{S i}(t)-\mathrm{FC}^{S i}
$$

The benefit for the chain as a single unit is independent of the transfer from retailer to suppliers, but the benefit of the retailer and of the suppliers strongly depends on this transfer, and the transfer depends on the contract. In this document two contracts are considered: rebate and option contract. In a rebate contract the supplier offers one price per unit ordered $w^{S i}(t)$, and a rebate $r(t)$ for a number of units over passing a target or a number of units $G(t)$ fixed by the supplier. With an option contract, there is also one price per unit provided $w^{S i}(t)$, and an option premium $O P^{S i}(t)$ to be paid according on the variation of demand prevision from the initial order to the final order.

In both contracts, the price over the market must be bigger than the prices for the retailer: $p(t)>w^{S i}(t)+c^{R}(t)$ to have a benefit from sales. For the option contract, beside this condition, another condition exists: $w^{S i}(t)>h^{R}(t)$, so that stock is interesting.

In this analysis we suppose that inventory is handled by a base stock policy. Under this policy the optimal inventory level $Q$ is calculated from the stockout $(\beta)$ and inventory holding $(h)$ costs. The retailer will be able to determine how much he should have in stock at time $t$. The retailer will order a quantity of products to complete this level taking into account his inventory.

\section{Rebate Contract}

Under a rebate contract context, the supplier offers a rebate for the units ordered above a rebate level $\mathrm{G}(\mathrm{t})$. The benefit for the retailer and each supplier will be, respectively:

$$
\begin{aligned}
& \pi^{R-R}(t)=p(t) S^{R}(t)-c^{R}(t) \sum_{i=1}^{\mathrm{I}} S^{S i}(t)-h^{R}(t) I^{R}(t)-F C^{R}-T S(t) \\
& \pi^{S i-R}(t)=T S^{S i-R}(t)-c^{S i}(t) M^{S i}(t)-F C^{S i}
\end{aligned}
$$

The suffix $\mathrm{R}$ was added to the variables whose value will be different under this context of rebate contract. If we consider that there is only one retailer and one supplier, their benefit will be:

$$
\begin{aligned}
& \pi^{R-R}(t)=p(t) S^{R}(t)-c^{R}(t) S^{R}(t)-h^{R}(t) I^{R}(t)- \\
& -F C^{R}-\left(w^{S-R}(t) Q(t)-\mathrm{r} \operatorname{Max}(Q(t)-\mathrm{G}(\mathrm{t}) ; 0)\right) \\
& \pi^{S-R}(t)=w^{S-R}(t) Q(t)-\mathrm{r} \operatorname{Max}(Q(t)-\mathrm{G}(\mathrm{t}) ; 0)-c^{S}(t) M^{S}(t)-\mathrm{FC} S
\end{aligned}
$$

In (5) and (6) the suffix $i$ was eliminated since there is only one supplier. It is important to notice that the number of units sold by the retailer at time $t, S^{R}(t)$ is different from the amount of units sold by the supplier and paid to her, this is: $S^{R}(t) \neq S^{S}(t)$. The first term is for the sales of the retailer over the final market and the second one for the sales of the supplier to the retailer. 
The transfer for a supplier with a capacity reservation contract is calculated from the two situations that may occur:

- If the ordered quantity $Q^{S i}(t)$ is smaller than or equal to the rebate quantity $\mathrm{G}(\mathrm{t})\left(Q^{S i}(t) \leq \mathrm{G}(\mathrm{t})\right)$, there will not be a rebate and the transfer will be for the unitary price per ordered unit:

$$
T S(t)=w^{S-R}(t) Q^{S i}(t)
$$

- If the ordered quantity $Q^{S i}(t)$ at time $\mathrm{t}$ is bigger than the rebate quantity $\mathrm{G}(\mathrm{t})\left(Q^{S i}(t)>\mathrm{G}(\mathrm{t})\right)$, there will be a rebate for the units overpassing $\mathrm{G}(\mathrm{t})$, so the transfer sill be for the unitary price per unit ordered minus the rebate for the units above $\mathrm{G}(\mathrm{t})$ :

$$
T S(t)=w^{S-R}(t) Q^{S i}(t)-r\left(Q^{S i}(t)-\mathrm{G}(\mathrm{t})\right)
$$

\section{Option Contract}

As previously explained, uncertainty comes from demand, so the retailer and the suppliers offering this contract will agree to accept modifications on the ordered quantity when they have a more clear idea about demand. There exist call and put options. When demand is higher than the initial estimation, then the retailer will exercise a call option, since he will order more than initially planned. When demand is smaller than the initial estimation a put option will be exercised by the retailer, since the order will be smaller. To modify the ordered quantity, the retailer will have to pay an option premium $O P^{S i}(t)$ to supplier $i$.

The option premium for a call option is:

$$
O P^{S i^{c}}(t)=C_{R} \frac{1}{r}\left[\frac{r-d}{u-d} \operatorname{Max}(\operatorname{Du}(\mathrm{t})-X(t), 0)+\frac{u-r}{u-d} \operatorname{Max}(\operatorname{Dd}(t)-X(t), 0)\right]
$$

The option premium for a put option is:

$$
O P^{S i P}(t)=C_{R} \frac{1}{r}\left[\frac{r-d}{u-d} \operatorname{Max}(X(t)-D u(t), 0)+\frac{u-r}{u-d} \operatorname{Max}(X(t)-D d(t), 0)\right]
$$

(7) and (8) come from the Cox-Ross-Rubinstain pricing model. The conversion rate $C_{R}$ gives the economical dimension to the result. The benefit for the retailer and the supplier $i$ will be:

$$
\begin{aligned}
& \pi^{R-O}(t)=p(t) S^{R}(t)-c^{R}(t) \sum_{i=1}^{\mathrm{I}} S^{S i}(t)-h^{R}(t) I^{R}(t)-F C^{R}-T S(t) \\
& \pi^{S i-O}(t)=T S^{S i-O}(t)-c^{S i}(t) M^{S i}(t)-\mathrm{FC}^{S i}
\end{aligned}
$$

The suffix $\mathrm{O}$ was added to the variables that will be different under the context of an option contract. If we consider that there is only one retailer and one supplier, their benefit will be: 


$$
\begin{aligned}
& \pi^{R-O}(t)=p(t) S^{R}(t)-c^{R}(t) S^{R}(t)-h^{R-O}(t) I^{R}(t)-F C^{R}-w^{S-O}(t) Q(t)-O P^{S}(t) \text { (11) } \\
& \pi^{S-O}(t)=w^{S-O}(t) Q(t)+O P^{S}(t)-c^{S}(t) M^{S}(t)-F C^{S}
\end{aligned}
$$

Again, the suffix $i$ was eliminated in (11) and (12) to consider one supplier. This time, the amount paid to the supplier will be for the ordered quantity. The number of units sold by the retailer will depend on demand and the number of units sold by the supplier will depend on the command from the retailer, this is: $S^{R}(t) \neq S^{S}(t)$.

\section{Analysis}

The price offered under a rebate context when the order overpass the rebate quantity will be smaller than the price offered under an option contract context, and both prices will be smaller than the price over the final market.

Since the price of the supplier will be bigger than her production cost under a rebate context $\left(w^{S-R}(t)-r^{S-R}(t)>c^{S}(t)\right)$ as well as for an option contract context $\left(w^{S-}\right.$ $\left.{ }^{O}(t)>c^{S}(t)\right)$, then the sum of production cost and wholesale price for an option contract will be bigger than the production cost for the supplier plus the wholesale price minus the rebate for a rebate contract context: $\left.\left(c^{R}(t)+w^{S-O}(t)>c^{S-R}(t)\right)+\left(w^{S-R}(t)-r^{S-R}(t)\right)\right)$. Inventory holding cost for the retailer under a rebate contract context will be equal or bigger than his cost under an option contract context: $h^{R-R}(t) \geq h^{R-O}$. The opportunity cost for the retailer, is different according to the contract. For a rebate contract, it is the price over the final market minus the wholesale price plus the rebate minus the production cost $\left(\beta^{R}(t)=p(t)-w(t)+r-c^{R}(t)\right)$.

The profit for the dyadic chain is calculated by:

$$
\Pi(t)=p(t) S^{R}(t)-c^{R}(t) S^{R}(t)-F C^{R-} c^{S}(t) M^{S}(t)-h^{R}(t) I^{R}(t)-\mathrm{FC}^{S}
$$

In order to understand under which context the chain will receive a bigger profit, a simulation plan was designed.

The benefit for the chain is calculated as the sum of the benefit for the retailer and the benefit for the supplier $\left(\Pi(t)=\pi^{R}(t)+\pi^{S}(t)\right)$; this was represented on (15). Te actual benefit for the retailer will depend on his sales and his costs (production, inventory holding and the transfer), and the benefit for the supplier on her sales (the transfer received from the retailer) and her costs. The transfer depends on the contract. If the transfers are compared, a retailer with a rebate contract with his supplier will have more benefit if the rebate is smaller than the option premium in the option contract, this is, if: $r \operatorname{Max}(Q(t)-\mathrm{G} ; 0) \leq O P^{S}(t)$. Since the results will depend on demand and its variability, it was decided to proceed with a simulation plan considering a uniform demand. The simulation compares the results for both contracts with identical prices, fix costs and demand; the difference will be given by the transfer, which will consider a rebate for the rebate contract and an option premium for the option contract.

\section{Methodology}

An analytical analysis was first developed to establish the benefit for the two companies of the dyadic chain under both contracts and for the chain as a single 
unit. Each contract has particular parameters that differentiate them. These parameters have been presented.

In order to compare the performance of the contracts, several situations were simulated for one retailer and one supplier from a supply chain. The value given in all simulations to the parameters were: $p(t)=22, c^{R}(t)=2, h^{R}(t)=1, F C^{R}=200, F C^{S}=100$.

From one simulation to another two elements were modified: the pricing scheme (the rebate) for rebate contract and the conversion rate for option contract. For the rebate contract four pricing schemes were simulated, in each one the rebate increases. The second element that was modified was the conversion rate. In (GomezPadilla and Mishina, 2009) it was shown that a conversion rate of 1 results in a better performance, so it was decided to consider three conversion rates: 1, a lower one and a higher one. From the simulation results of (Gomez-Padilla and Mishina, 2009), it was then decided to use three conversion rates: $c_{R}=0.75, c_{R}=1$ and $c_{R}=1.5$. The simulations were done for a uniform demand.

For the option contract, the value given to the parameters to calculate the call and put options were: $r=1, d=0.8$ and $u=1.2$. For a rebate contract, the price is constant, but the rebate increases in order to have a situation where this contract becomes more and more interesting this contract: on the first one the rebate represents a $7 \%$ of price reduction, the second $14 \%$, the third $21 \%$ and the fourth $35 \%$. For both contracts $\mathrm{w}=14$ in all cases.

The base stock level is calculated considering the inventory holding cost (which is constant) and the backorder cost (which is different for each contract). The backorder cost depends on the transfer. For the rebate contract, the level from which the rebate starts was fixed as the base stock level for a wholesale price contract, and the base stock level was the one calculated considering the rebate contract. There is then a different base stock level for each rebate. For the option contract, the base stock level changes with the option premium.

There were then simulated 12 different situations for the same demand pattern (4 pricing schemes for the rebate contract and 3 conversion rates for the option contract). Each situation considered 12 periods of time and was repeated 100 times. The results analyzed in this section correspond to the average result of each. The simulations were handled using Visual Basic and Excel 2007.

For a given set of parameters (the 12 previously described), two situations are compared: one when the contract between the supplier and the retailer is a rebate one and another it is an option contract. The retailer fixes its inventory level according to his parameters: for a rebate contract the inventory level changes when the rebate changes and for the option contract the inventory level may change from one period to the other. The retailer will pass the order to the supplier for a quantity according to his base stock level and to the inventory carried from the previous period. The supplier will send the command and then the demand will take place. The demand and the inventory left will determine the benefits for the supplier, the retailer and the chain.

The objective of simulations is to compare the results for the supplier, the retailer and the chain for both contracts. 


\section{Simulation Results}

The results compared are organized in two sets. The first set concerns economic results: the benefit for the chain as a whole and the gains for the retailer and the supplier. The second set concerns the physical flow of units.

Comparing the benefit for the chain, the rebate contract is more interesting for the chain than an option contract. This is because with a rebate contract the retailer will hold a higher base stock level and will be able to satisfy a bigger demand. Figure 2 shows the results for a conversion rate $C_{R}=0.75$; it is just presented one result since the results for other conversion rates have the same tendency.

In terms of gains, a rebate contract will increase the gains as well for the retailer than for the supplier. This is shown on Figure 3 for a conversion rate $C_{R}=1$. In this figure it is possible to see that the higher benefit for both is with a rebate contract with a rebate between 14 and $21 \%$.

Figure 4 shows the costs of inventory holding and backorder when demand is uniformly distributed for the four pricing schemes and the three conversion rates.

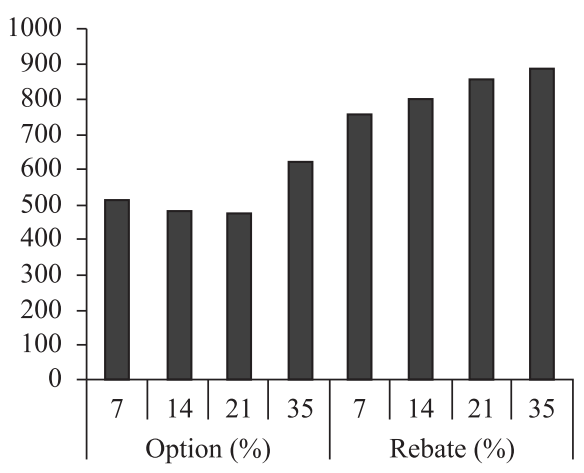

Figure 2. Benefit of the chain for $C_{R}=0.75$.

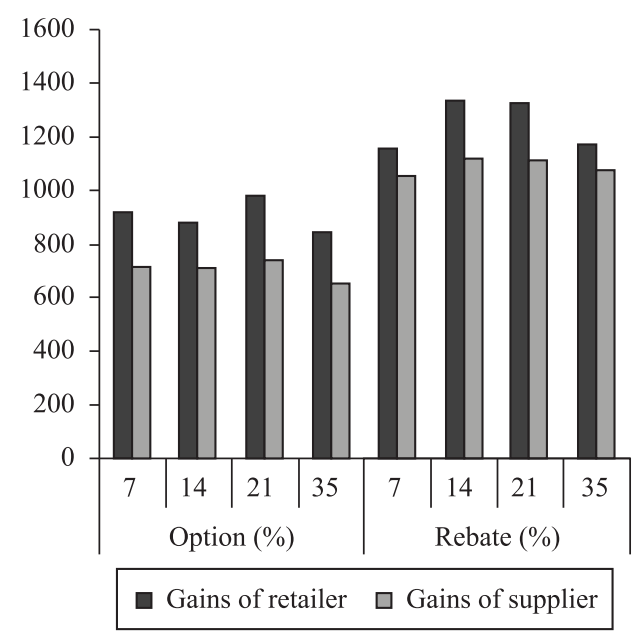

Figure 3. Gains for retailer and supplier $C_{R}=1.50$. 
The difference from one contract to the other in terms of inventory holding cost is not big compared to the difference in terms of backorder costs. Backorder costs are nearly null for a rebate contract while that, for an option contract, backorder costs represent more than the double than inventory holding costs.

Figure 5 shows the average units in stock hold by the retailer and the average lost sales for the 12 periods of time simulated 100 times. It is possible to appreciate on

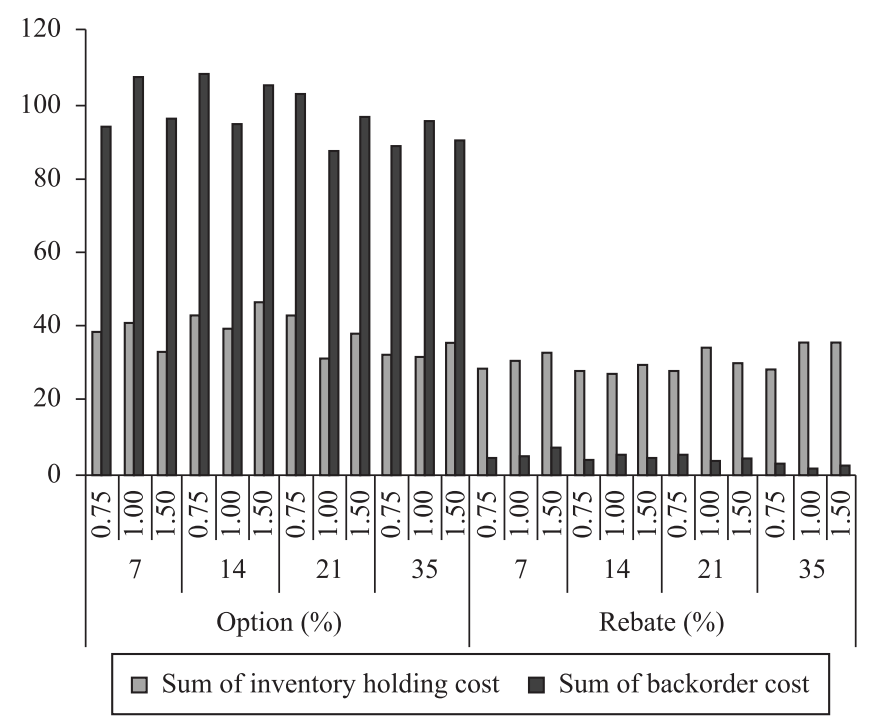

Figure 4. Inventory holding and backorder costs.

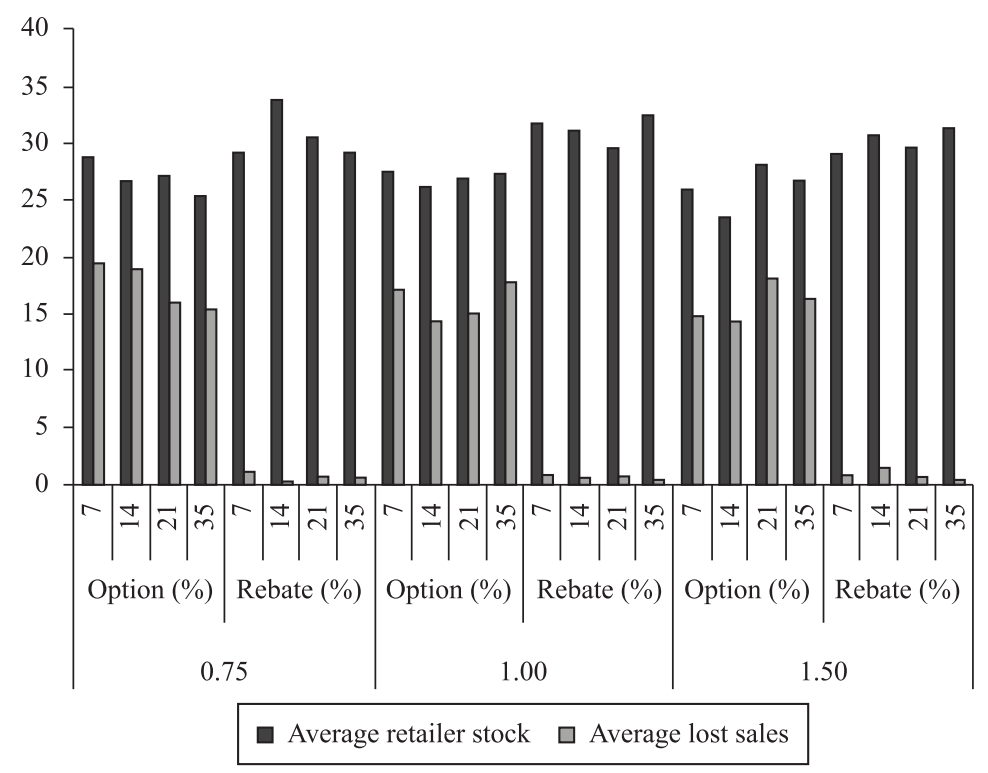

Figure 5. Average stock and lost sales for retailer. 
this figure that with a rebate contract, the retailer will hold a slightly bigger stock, but also that lost sales are practically inexistent.

On one hand, the retailer has a bigger base stock level with a rebate contract than with an option contract, so he is better prepared to afford variability of demand; on the other hand, with a rebate contract the ordered quantities will be bigger (he will buy more units to the supplier) and his costs will increase as well for the transfer to supplier than for his internal inventory holding cost.

The rebate contract is more interesting when the demand is uniformly distributed and when the conversion rates of the option contract are near $1: c_{R}=0.75$, $\mathrm{c}_{\mathrm{R}}=1$ and $\mathrm{c}_{\mathrm{R}}=1.5$. These two elements negatively affect the option contract results. On one hand, the considered demand distribution increases the option premium; since variations on demand are high, the option premium to pay is high. On the other hand, the values for the conversion rate decrease the base stock level that is held with an option contract; with a low base stock level (and big demand variation) the retailer will increase his probability of not being able to satisfy the demand and run out of stock. Here it is important to highlight that the decision of the conversion rates to considered was based on the results of (Gomez-Padilla and Mishina, 2009), but those results came from the model proposal; we consider that it is possible to identify a range of values for the conversion rate so that the option contract will give better results that the be a better decision.

\section{Conclusions}

From literature review it is possible to highlight the importance of contracts for coordination and that rebate and option contracts have been studied from different points of view and under different conditions. In this work we considered a rebate contract that in the literature has been identified as target rebate since the rebate is applied to the units over passing a target (or level) of units, and an option contract that in the literature is identified as bidirectional options. The purpose is to compare the performance of both contracts in terms of units exchanged and in terms of economic results. The model was proposed first for one retailer and multiple suppliers, and then for one retailer and one supplier under a rebate and an option contract. The expected benefit for the retailer and the supplier under each contract were modeled, considering their respective transfer. Since the results will depend on demand variation, a simulation plan was proposed. The simulation plan consisted of 12 situations for a uniform demand. The variations were the rebate for the rebate contract and the conversion rate for the option contract. For the rebate contract, 4 rebates were considered: 7, 14, 21 and 35\%. For the option contract, 3 conversion rates were considered: $0.75,1$ and 1.5.

A rebate contracts increases the benefit for the chain as well as the gains for retailer and supplier. With a rebate contract the retailer passes bigger orders because the base stock is higher; the retailer increases his sales (and gains more) because he has more stock to face demand, and the supplier increases his sales (and gains more) because the retailer orders bigger quantities.

From the results of simulation, it is also possible to conclude that, under a uniform demand and for conversion rates near 1, a rebate contract is more convenient for the retailer in terms of backorder cost reduction. In terms of inventory holding cost 
the rebate contracts is slightly smaller, even though with a rebate contract the retailer holds more stock. The reason for this is that demand is usually as big as the base stock level for a rebate contract, and with an option contract, the base stock level is smaller, so he will have lost sales. The inventory holding cost is not big $\left(h^{R}(t)=1\right)$, while the backorder cost is higher (it changes according to the contract and its parameters).

The insights of this research that would be important for practitioners are two: 1) offering rebates based on a target may increase the benefit for the chain and 2) even though the tendencies are toward zero stock policies, increasing the inventory may lead to increase the benefit because you have enough units to satisfy demand; this is particularly important when the market is a lost sales one. The insights of this research that would be important for researchers are related to the contract model development and the establishment of parameters to achieve coordination in supply chains.

It is important to mention that the retailer may have negative results because of costs in both contracts. The rebate contract is better because the retailer pays less for the units, while in the option contract the retailer will always pay more. This leads to identify that further research should be done considering different rebate schemes, other conversion rates, and different holding stock prices to identify when a rebate contract stops being more advantageous. Different demand patterns should be also considered.

\section{References}

Bassok, Y. and Anupindi R. (1997) Analysis of supply contracts with total minimum commitment. IIE Transactions, Vol. 29, No. 5, pp. 373-381. http://dx.doi. org/10.1080/07408179708966342

Chen, Y. (2011) Returns with wholesale-price-discount contract in a newsvendor problem, International Journal of Production Economics, Vol. 130, No. 1, pp. 104-111. http:// dx.doi.org/10.1016/j.ijpe.2010.11.025

Chiu, C.H.; Choi, T.M. and Tang C.S. (2011) Price, Rebate, and Returns Supply Contracts for Coordinating Supply Chains with Price-Dependent Demands. Production \& Operations Management, Vol. 20, No. 1, pp. 81-91. http://dx.doi.org/10.1111/j.19375956.2010.01159.x

Edlin, A.S. and Hermalin B.E. (2000) Contract renegotiation and options in agency problems. Journal of Law Economics and Organization, Vol. 16, pp. 395-423. http://dx.doi. org/10.1093/jleo/16.2.395

Gomez Padilla, A. and Mishina, T. (2009) Supply contracts with options. International Journal of Production Economics, Vol. 122, No. 1, pp. 312-318. http://dx.doi.org/10.1016/j. ijpe.2009.06.006

Gu, Z. and Yang, S. (2010) Quantity-Discount-Dependent Consumer Preferences and Competitive Nonlinear Pricing. Journal of Marketing Research, Vol. 47, No. 6, pp. 1100-1112. http://dx.doi.org/10.1509/jmkr.47.6.1100

Hassini, E. (2008) Order lot sizing with multiple capacitated suppliers offering leadtime-dependent capacity reservation and unit price discounts. Production Planning \& Control, Vol. 19, No. 2, pp. 142- 149. http://dx.doi.org/10.1080/09537280801896177

Jain, K. and Silver, E.A.(1995) The single period procurement problem where dedicated supplier capacity can be reserved. Naval Research Logistics, Vol. 42, No. 6, pp. 915-934. http:// dx.doi.org/10.1002/1520-6750(199509)42:6\%3C915::AID-NAV3220420605\%3E3.0.CO;2-M 
Jin, M. and Wu, S. D. (2007) Capacity reservation contracts for high-tech industry. European Journal of Operational Research, Vol. 176, No. 3, pp. 1659-1677. http://dx.doi. org/10.1016/j.ejor.2005.11.008

Kamrad, B. and Siddique, A. (2004) Supply contracts, profit sharing, switching, and reaction options. Management Science, Vol. 50, No. 1, pp. 64-82. http://dx.doi.org/10.1287/ mnsc. 1030.0157

Kurata, H. and Yue, X. (2008) Trade promotion mode choice and information sharing in fashion retail supply chains. International Journal of Production Economics, Vol. 114, No. 2 , pp. 507-519. http://dx.doi.org/10.1016/j.ijpe.2007.05.021

Liu, L. and Wang, L. (2007) Management strategy of materials supply for manufacturing organizations. Computers \& Industrial Engineering, Vol. 53, No. 2, pp. 326-349. http://dx.doi.org/10.1016/j.cie.2007.06.026

Lu, X.W.; Song, J.S. and Regan A. (2007) Rebate, returns and price protection policies in channel coordination. IIE Transactions, Vol. 39, No. 2, pp. 111-124. http://dx.doi. org/10.1080/07408170600710408

Natz, A. (2008) Risks and chances in the Germanic generic market. Journal of Generic Medicines, Vol. 5, No. 2, pp. 99-103. http://dx.doi.org/10.1057/palgrave.jgm.4950104

Nocke, V.; Peitz, M. and Rosar, F. (2011) Advance-purchase discounts as a price discrimination device. Journal of Economic Theory, Vol. 146, No. 1, pp. 141-162. http://dx.doi. org/10.1016/j.jet.2010.07.008

Schneeweiss, C.; Zimmer, K. and Zimmermann M. (2004) The design of contracts to coordinate operational interdependencies within the supply chain. International Journal of Production Economics, Vol. 92, No. 1, pp. 43-59. http://dx.doi.org/10.1016/j.ijpe.2003.10.005

Taylor, T.A. (2002) Supply Chain Coordination under Channel Rebates with sales effort effect. Management Science, Vol. 48, No. 8, pp. 992-1007. http://dx.doi.org/10.1287/ mnsc.48.8.992.168

Wang, Q. and Tsao, D. (2005) Supply contract with bidirectional options: the buyer's perspective. International Journal of Production Economics, Vol. 104, No. 1, pp. 30-52.

Wang, X. and Liu, L. (2007) Coordination in a retailer-led supply chain through option contract. International Journal of Production Economics, Vol. 110, No.1-2, pp. 115-127. http://dx.doi.org/10.1016/j.ijpe.2007.02.022

$\mathrm{Xu}$, H.A. (2010) Managing production and procurement through option contracts in supply chains with random yield. International Journal of Production Economics, Vol. 126, No. 2, pp. 306-313. http://dx.doi.org/10.1016/j.ijpe.2010.04.007

Yang, J. and Qi, X. (2009) On the design of coordinating contracts. International Journal of Production Economics, Vol. 122, No. 2, pp. 581-594. http://dx.doi.org/10.1016/j. ijpe.2009.06.002

Zhang, L.; Song, S.J. and Wu C. (2005) Supply chain coordination of loss-averse newsvendor with contract. Tsinghua Science and Technology, Vol. 10, No. 2, pp. 133-140. http:// dx.doi.org/10.1016/S1007-0214(05)70044-4

\section{Biography}

Alejandra Gomez-Padilla is an associate professor at the Department of Industrial Engineering at the Center of Exact Sciences and Engineering of University of Guadalajara, in Mexico. She pursued her undergraduate studies on industrial engineer in Mexico and holds a master's degree from the École Polytechnique de Montréal (Polytechnic School of Montreal). She obtained a doctorate degree on industrial engineering at the National Polytechnic Institute of Grenoble, in France. Before joining 
academia, she worked for IBM Mexico Site as Production and Product Engineer. Her research interests are in areas of logistics, optimization and supply chain modeling, specifically models that include contracts.

Contact: alejandra.gomez@cucei.udg.mx

Tsutomu Mishina is professor at the Department of Management Science and Engineering of Akita Prefectural University, in Japan.

Contact: mishina@akita-pu.ac.jp

\section{Article Info:}

Received: September, 2011

Accepted: December, 2011 